\title{
Elucidating the Potential of Native Rhizobial Isolates to Improve Biological Nitrogen Fixation and Growth of Common Bean and Soybean in Smallholder Farming Systems of Kenya
}

\author{
Ernest Wandera Ouma, Anne Mercy Asango, John Maingi, and Ezekiel Mugendi Njeru \\ Department of Microbiology, Kenyatta University, P.O. Box 43844-00100, Nairobi, Kenya
}

Correspondence should be addressed to Ezekiel Mugendi Njeru; njeruezek@gmail.com

Received 22 June 2016; Accepted 24 August 2016

Academic Editor: Manuel Tejada

Copyright (C) 2016 Ernest Wandera Ouma et al. This is an open access article distributed under the Creative Commons Attribution License, which permits unrestricted use, distribution, and reproduction in any medium, provided the original work is properly cited.

\begin{abstract}
Identification of effective indigenous rhizobia isolates would lead to development of efficient and affordable rhizobia inoculants. These can promote nitrogen fixation in smallholder farming systems of Kenya. To realize this purpose, two experiments were conducted under greenhouse conditions using two common bean cultivars; Mwezi moja (bush type) and Mwitemania (climbing type) along with soybean cultivar SB 8. In the first experiment, the common bean cultivars were treated with rhizobia inoculants including a consortium of native isolates, commercial isolate (CIAT 899), a mixture of native isolates and CIAT 899, and a control with no inoculation. After 30 days, the crop was assessed for nodulation, shoot and root dry weights, and morphological features. In the second experiment, soybean was inoculated with a consortium of native isolates, commercial inoculant (USDA 110), and a mixture of commercial and native isolates. Remarkably, the native isolates significantly $(p<0.001)$ increased nodulation and shoot dry weight across the two common bean varieties compared to the commercial inoculant, CIAT 899. Mixing of the native rhizobia species and commercial inoculant did not show any further increase in nodulation and shoot performance in both crops. Further field studies will ascertain the effectiveness and efficiency of the tested indigenous isolates.
\end{abstract}

\section{Introduction}

Despite record-high economic growth rates over the past five years, Sub-Saharan Africa (SSA) still remains by far the poorest region of the world [1]. This is attributed to the state of food security in SSA undermined by widespread poverty and little use of modern farming and production-enhancing technologies. Many countries in SSA including Kenya are food insecure. Food insecurity is directly linked to various causes such as low soil fertility, diseases, and practice of extractive and unsustainable farming procedures like continuous cropping [2]. Therefore, to address the problem of decreasing food production and livelihoods resulting from declining soil fertility, the conservation and sustainable use of soil microorganisms are critical [3]. Many farmers in SSA are not able to purchase the expensive mineral nitrogen fertilizers.

Chemical $\mathrm{N}$ fertilizer application is not recommended as it is responsible for about $70 \%$ of greenhouse gas (GHG) emissions. The GHGs release is associated with the production of crops through both the fossil energy used during fertilizer manufacture and $\mathrm{N}_{2} \mathrm{O}$ emissions from the soil subsequent to application. Biological nitrogen fixation has been found to be 3 to 4 times efficient over the $\mathrm{N}$ fertilizers, besides offering an environmentally sound source of $\mathrm{N}$ to cropping systems [4]. Therefore, BNF can be used as a good supplement reducing amount of $\mathrm{N}$ fertilizers used by smallholder farmers thus reducing both economic and environmental costs [5]. Soil microorganisms such as rhizobia can be used as inoculants to assist in alleviating soil infertility. This is due to their ability to infect leguminous plant's roots and fix nitrogen in the soil.

Common bean (Phaseolus vulgaris L.) and soybean (Glycine Max) are suitable for growing in SSA region because they perform well under limited supply of soil nutrients and have resistance to a number of pests and pathogens. These leguminous crops fix nitrogen in a symbiotic association with 
rhizobia. In addition, beans have high nutritional content for use by the malnourished populations in the region. Common bean is the major grain legume crop in SSA [6] and in Kenya where total dry bean production was 615992 tonnes by year 2014 ([7], accessed on 1st August 2016). Growing of soybean is not widely practiced in Kenya due to other unappreciated benefits of the crop such as the potential to contribute to biofuel energy [8]. Although the two crops have potential to perform well and fix nitrogen for the succeeding crops, their production in SSA still remains low. Moreover, the use of commercial rhizobia inoculants to improve the performance of these crops is limited due to the high cost of the cultures, limited information on inoculation benefits, and poor performance of the exotic cultures due to lack of adaptation to local agroclimatic conditions or negative microbial interactions. Besides, the availability of highly effective native rhizobia in Kenyan soils has not been exploited considering that the current commercial inoculants used in the country mainly contain exotic strains [9].

Here we tested the hypotheses that different rhizobia strains nodulate common bean and soybean crops with variation in $\mathrm{N}$ fixation efficiency and effectiveness. The specific aims of the study were (1) to compare nodulation and nitrogen fixation effectiveness of native rhizobia isolates versus commercial strain CIAT 899 or USDA 110, (2) to determine the effect of increasing rhizobia species diversity by mixing commercial strain and native strains on nodulation and nitrogen fixation, and (3) To determine the effect of common bean cultivar (climbing versus bush type) on nodulation and nitrogen fixation.

\section{Materials and Methods}

\subsection{Experiment 1}

2.1.1. Rhizobia Cultures. Indigenous rhizobia isolates were obtained from field trap cultures of common beans grown in smallholder farms in Kisumu County, Kenya. Desiccated root nodules were reactivated overnight in distilled water at $4^{\circ} \mathrm{C}$. The nodules were sterilized with $3 \%$ sodium hypochlorite solution for 2 minutes, rinsed 6 times in distilled water, and then crushed in a drop of sterile water. A loopful of the derived suspension was streaked on Yeast Extract Mannitol Agar (YEMA) with Congo Red (CR) and Bromothymol Blue (BTB) and then incubated at $28^{\circ} \mathrm{C}$ [10]. The commercial isolate CIAT 899 was obtained from MEA Fertilizer Company Limited, Nakuru, Kenya. The indigenous rhizobia isolates were grouped as fast or slow growers depending on growth on YEMA with BTB. Isolates with visible colonies after 2 to 5 days were considered fast growers while those taking more than 5 days were considered to be slow growers. Colony characteristics of isolates observed included colony shape, Gram stain, colony elevation, colony consistency, colour, opacity, texture, size, and shape of margins.

2.1.2. Experimental Design. The experiments were laid out in a completely randomized design with bean variety as the main factor and rhizobia inoculation as the subfactor. The bean varieties included Mwitemania (climbing type) and
Mwezi moja (bush type) obtained from Kenya Seed Company, Nairobi, Kenya. The two bean varieties are commonly grown by smallholder farmers in Kenya and are mainly used as food or sold at local markets. Rhizobia inoculants were a consortium of native isolates obtained from the field trap cultures, commercial isolate CIAT 899, a combination of native consortium and commercial isolate $(1: 1 \mathrm{v} / \mathrm{v})$, and a negative control (no inoculation or nitrogen source addition). Healthy bean seeds were sterilized in 95\% alcohol for 10 seconds followed by $3 \%$ of sodium hypochlorite $(\mathrm{NaOCl})$ for 3 minutes and then the seeds were rinsed with 8 changes of distilled water. The experimental soil obtained from Kenyatta University farm had the following physical-chemical characteristics: sand $65 \%$, silt $12 \%$, clay $23 \%$, pH (water) 5.93 , organic C, $2.8 \%$, N 0.24\%, exchangeable K $2.7 \mathrm{cmol} \mathrm{kg}^{-1}$, Na trace, Ca $9.1 \mathrm{cmol} \mathrm{kg}^{-1}, \mathrm{Mg} 3.65 \mathrm{cmol} \mathrm{kg}^{-1}$, CEC $13.40 \mathrm{cmol} \mathrm{kg}^{-1}$, and available $\mathrm{P}$ (CAL) $14.40 \mathrm{mg} \mathrm{kg}^{-1}$. The soil was then mixed with quartz sand $(1: 1 \mathrm{v} / \mathrm{v})$ to provide oxic conditions for root and microbial respiration and sterilized overnight at $80^{\circ} \mathrm{C}$. The mixture was put in clean 32 plastic pots (washed with liquid soap and $3 \% \mathrm{NaOCl}$ and then wiped with cotton soaked in $70 \%$ ethanol before soil packaging). The packed soil was covered on top with a layer of gravel to avoid contamination from the surroundings.

2.1.3. Maintenance of the Growing Crop. The plants in pots were irrigated with distilled water after every 4 days during the entire growth period after planting to provide sufficient water for germination and proper growth. Irrigation was achieved by adding water through a vertically pegged pipe in the soil to avoid washing into soil the deposited microorganisms on the gravel surface. After 7 days, thinning was done to reduce the plants to one plant pot $^{-1}$ and inoculation done whereby $1 \mathrm{~mL}$ of rhizobia broth culture was introduced for each treatment. The Mwitemania variety was staked with long sticks pegged in the soil to maintain upright growth.

2.1.4. Plant Harvesting and Analyses. Harvesting was done after 30 days. The shoots were cut at the level where the soil reached. The roots and adhering soil clods were placed on a course sieve for washing using a gentle stream of water. The root and shoot lengths were measured. The roots were observed for the presence of nodules, nodule number was determined, and then the nodules were detached and then placed in an absorbent paper separately for each individual plant. The nodules were dried at $65^{\circ} \mathrm{C}$ for 24 hours [11] and their dry weight was recorded in $\mathrm{mg} \mathrm{plant}^{-1}$. The shoot and roots with no nodules were placed in cellulose paper bags separately for each root and shoot and for each plant and thereafter dried for 48 hours at $70^{\circ} \mathrm{C}$ and weighed in g plant ${ }^{-1}$.

\subsection{Experiment 2}

2.2.1. Rhizobia Cultures. Soil samples were collected aseptically from smallholder farms in Embu and Tharaka-Nithi Counties of Kenya where subsistence farming of legumes is predominant. Embu County is located at the foot of Mt. Kenya at $0.53^{\circ} \mathrm{S}, 37.45^{\circ} \mathrm{E}$ within an elevation of $1100-$ $1500 \mathrm{~m}$ above sea level while Tharaka-Nithi County is on 
the southeastern side of Mt. Kenya at $0.30^{\circ} \mathrm{S}, 38.06^{\circ} \mathrm{E}$ and lies at an elevation of 600-1500 m above sea level. Soybean is among the major food crops produced in the counties, although its production is lower than other key legumes in the area including common bean and cowpea. Soil sampling was carried out across 8 smallholder farms (four in each county), diagonally at 10 points in every farm at fixed intervals before the onset of rains. The soil was eventually homogenously mixed to form one composite sample which was sandy loam with the following characteristics: $\mathrm{pH}$ (water) 5.45, organic $\mathrm{C}$, $2.95 \%, \mathrm{~N} 0.30 \%$, exchangeable $\mathrm{K} 0.90 \mathrm{cmol} \mathrm{kg}^{-1}$, and available $\mathrm{P}$ (CAL) $23.0 \mathrm{mg} \mathrm{kg}^{-1}$.

Native rhizobia were obtained by diluting the soil in distilled water and inoculating $1 \mathrm{~mL}$ of the soil suspension on YEMA and incubated at room temperature for 4 days. Subculturing was then carried out on YEMA with CR and incubated at $28^{\circ} \mathrm{C}$ for 4 days. Subculturing was done from which the isolates were characterized morphologically. Colony characteristics of isolates observed were as above (Section 2.1.1). The isolates were tested for acid or alkali production by growing them on YEMA with BTB. Based on morphological and biochemical tests, native rhizobia were clustered as either isolate 1 or 2 , while all the other isolates including 1 and 2 were clustered as a native consortium.

2.2.2. Experimental Design. The experiment was laid out in a completely randomized design with rhizobia inoculation being the main factor. This included inoculation of the promiscuous soybean cultivar SB 8 with native isolate 1 or 2 , consortium of native strains, commercial inoculant USDA 110 , nitrogen treated, and the standard control with nitrogenfree medium. Each treatment was then replicated five times making a total of 30 Leonard jar assemblies. The jars were filled with sterile nitrogen-free vermiculite as the rooting medium for the soybeans. The sterile vermiculite-loaded jars were then placed in brown khaki bags and steam sterilized to reduce the microbial load on the bags. Before planting soybean seeds were surface-sterilized in five changes of distilled water and soaked in 3\% sodium hypochlorite for 3 minutes.

2.2.3. Maintenance of the Growing Crop. The jars were irrigated after every two weeks with Broughton and Dilworth solutions which were used as a source of nutrients for the plants [10]. The nitrogen treated plants were fertilized with potassium nitrate solution.

2.2.4. Plant Harvesting and Analyses. After 35 days the soybeans were uprooted and gently washed. Nodules were carefully detached and counted and nodulation was scored as positive when seedlings bore at least a single nodule and as negative if no nodules were formed. The nodules were then dried at $65^{\circ} \mathrm{C}$ for 24 hours [11] and their dry weight was recorded in mg plant ${ }^{-1}$. The shoots and roots with no nodules were placed in cellulose paper bags separately and thereafter all shoots and roots were dried for 48 hours at $70^{\circ} \mathrm{C}$ and weighed in g plant $^{-1}$.

2.3. Statistical Analyses. Data on nodule number, nodule dry weight, shoot length and shoot dry weight, root length, and root dry weight was tested for homogeneity of variance using Bartlett's test and subjected to one-way ANOVA using SPSS version 20 computer program. The data reported in tables was back-transformed. Post hoc analysis was done using Tukey's HSD test at $p<0.05$ to separate means.

\section{Results}

Two native rhizobia groups were recovered from the desiccated common bean root nodules. The rhizobia CBRN-1 and CBRN-2 did not absorb Congo Red dye and were Gram negative rods. The colonies were round in shape, mucoid, glistening, with a convex elevation, translucent, and smooth margined. CBRN-1 colonies had a diameter of about $5 \mathrm{~mm}$ and CBRN-2 colonies $3 \mathrm{~mm}$ as observed after 3 days. The strains turned BTB to yellow.

Statistical analyses showed significant effect $(p<0.001)$ of inoculation on nodulation of both common bean varieties. Inoculation with the consortia of indigenous strains showed higher nodule number plant ${ }^{-1}$ and nodule dry weight compared to CIAT 899 (Table 1). However, mixing CIAT 899 and the native consortia did not result in further increase in nodulation. Bean variety did not significantly affect both nodule number plant ${ }^{-1}$ and nodule dry weight. Moreover, there was no significant interaction between bean variety and rhizobial inoculation for both parameters.

The crops had indistinctive variation in shoot colour for all the treatments and the negative control. However, the plants treated with rhizobia had higher shoot dry weight and height than negative controls indicating that $\mathrm{N}$ was fixed. Both rhizobia inoculation and variety significantly $(p=0.001)$ affected plant shoot height. Inoculation with indigenous rhizobia isolates showed the highest shoot height $(66.1 \mathrm{~cm})$ followed by a mix of indigenous isolates and CIAT $899(64.7 \mathrm{~cm})$ while no inoculation recorded the lowest shoot height $(45.4 \mathrm{~cm})$. There was a significant interaction $(p=$ 0.007 ) between variety and rhizobia inoculation in improvement of plant shoot height. Shoot dry weights were significantly affected $(p=0.001)$ by both inoculation $(p=0.001)$ and bean variety. The highest shoot dry weight $\left(1.62 \mathrm{~g} \mathrm{plant}^{-1}\right)$ was for a combination of indigenous isolate and CIAT 899 which was significantly higher than CIAT 899 when used independently (Table 2). There was no significant interaction $(p=0.753)$ between rhizobia inoculation and variety in affecting shoot dry weight (Table 2). Root length, root dry weight, and shoot/root ratio were not significantly affected by any of our treatments and the interaction between treatments (Table 2).

In experiment 2, two key rhizobia strains were isolated from the soil samples collected. Isolate 1 was morphologically large, mucoid, dome shaped, translucent, and sticky while isolate 2 was milky/whitish, gummy, dome shaped, and mucoid and had a circular margin. The two isolates were Gram negative and when grown on BTB they both turned the media to yellow.

As expected, rhizobia inoculation significantly increased nodule number and nodule dry weight $(p<0.001 ; p=0.015$, resp.). Both the native consortium and commercial inoculant enhanced soybean nodulation contrary to native isolates 1 
TABLE 1: Nodule number and nodule dry weight $\left(\mathrm{mg} \mathrm{plant}^{-1}\right)$ as affected by rhizobia inoculants and bean variety.

\begin{tabular}{|c|c|c|}
\hline & Nodule number plant $^{-1}$ & Nodule dry weight (mg plant ${ }^{-1}$ ) \\
\hline \multicolumn{3}{|l|}{ Rhizobia inoculant } \\
\hline CIAT + CTM & $57 \pm 5.66^{\mathrm{a}}$ & $19.4 \pm 2.31^{\mathrm{a}}$ \\
\hline CIAT899 & $40 \pm 7.04^{\mathrm{b}}$ & $13.9 \pm 1.88^{\mathrm{b}}$ \\
\hline CTM & $57 \pm 8.50^{\mathrm{a}}$ & $24.6 \pm 2.83^{\mathrm{a}}$ \\
\hline Control & 0.0 & 0.0 \\
\hline \multicolumn{3}{|l|}{ Variety } \\
\hline Mwezi moja & $44 \pm 8.50^{\mathrm{a}}$ & $14.0 \pm 2.69^{\mathrm{a}}$ \\
\hline Mwitemania & $38 \pm 7.14^{\mathrm{a}}$ & $15.0 \pm 2.81^{\mathrm{a}}$ \\
\hline \multicolumn{3}{|c|}{$p$ values of the main factors and their interaction } \\
\hline Bean variety & 0.263 & 0.654 \\
\hline Rhizobia inoculant & 0.001 & 0.001 \\
\hline Rhizobia inoculant $\times$ variety & 0.217 & 0.659 \\
\hline
\end{tabular}

Means followed by same lowercase letter(s) are not significantly different at $p<0.05$ (Tukey's HSD test). CIAT 899: commercial isolate, CTM: consortium of indigenous isolates, and CIAT + CTM: commercial isolate + consortium of indigenous isolates.

and 2 (Table 3 ). The nitrogen treated and negative treatments did not induce any nodulation. Despite the low nodulation, native isolate 1 showed the highest mean shoot dry weight and the negative control had the lowest mean shoot dry weight (Table 3). Inoculation with the consortium of native isolates and the commercial isolate resulted in the highest root dry weight while inoculation with native isolate 2 showed the lowest root dry weight.

\section{Discussion}

Interestingly, in experiment 1, the two indigenous isolates authenticated as fast growing Rhizobium sp. were more effective in nodulation of the climbing bean compared to the commercially available CIAT 899. Such findings reflect presence of effective native rhizobia isolates in smallholder agroecosystems, which could further be developed into lowcost inocula and used to improve common bean production. The ineffectiveness of CIAT 899 may be attributed to soil characteristics like the low temperatures experienced during the cold rainy season or lack of adaptation to the soil conditions used in this study. Although the soil was relatively acidic ( $\mathrm{pH}$ 5.9), such $\mathrm{pH}$ is favourable for bean growth, rhizobia nodulation, and nitrogen fixation [12].

The rhizosphere environment affects Rhizobium sp. interaction with the common bean root hairs, nodulation, and nitrogen fixation [13]. The differences among the treatments in terms of shoot height, shoot dry weight, nodule number, and nodule dry weight have also been encountered in other studies with indigenous Rhizobium sp. and common bean $[11,14]$. Matching rhizobia and the legume host is important; hence increasing the diversity in species can increase the chances of getting a better match among the strains without use of more resources [13].

In this work, the native rhizobia isolates did not show preference for any bean cultivar since we did not observe any significant rhizobia inoculant and bean variety interaction. This opposes recent findings by Mehrpouyan [14] who reported a significant interaction between the two factors. Similarly, variety and rhizobia strains interaction was observed by Karasu et al., [15] resulting in increased shoot length.

The differences in height could have been due to responses of cultivars to varied concentrations of auxins produced by Rhizobium [16]. The cultivars differ in genetic constitution as phenotypically Mwitemania is a climbing type and Mwezi moja a dwarf type bringing about high variation in heights.

In experiment 2, no variation was seen in symbiotic effectiveness of the commercial inoculant and the native consortium. However, isolates 1 and 2 did not perform well contrary to our expectation. Nonetheless, despite the low nodule number showed by native isolate 1 , the isolate resulted in high shoot dry weight.

The number of nodules alone therefore may not reflect on the effectiveness of the treatment because isolate 1 had the highest symbiotic effectiveness value but had low nodule number compared to the USDA 110 and the consortium treatments which exhibited lower effective values. Denison and Kiers [17] suggested that rhizobia that fix little or no nitrogen could exhibit parasitic behavior. Similar findings were reported by [18] that reported that a great number of nodules can be formed by a strain fixing little or no nitrogen, even in the presence of effective strains. Hahn and Studer [19] reported that legumes cannot consistently recognize and exclude nonfixing rhizobia, especially those that are closely related to their usual symbiotic partners.

\section{Conclusion}

Interestingly in this study, we found that native isolates especially the consortium were more effective than the commercially available CIAT 899 in the case of common bean or performed similarly to USDA 110 in soybean. Therefore, the native isolates have great potential of being further developed to provide cheap and efficient inoculum to smallholder farmers in the study areas and beyond. Although mixing the commercial and native inoculum in experiment 1 did 


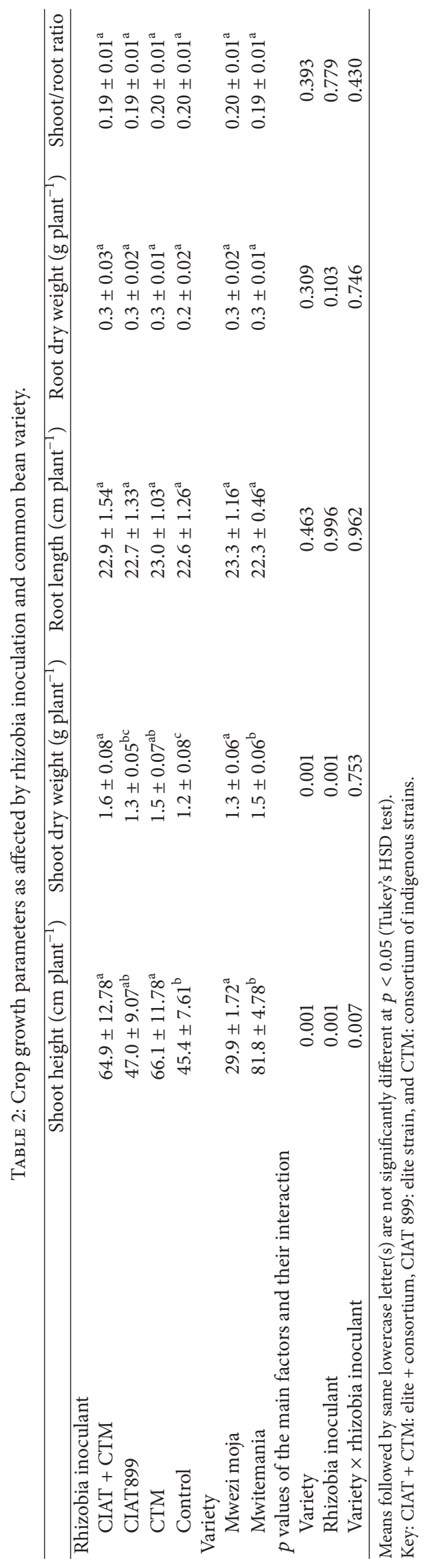


TABLE 3: Soybean growth parameters and nodulation as affected by rhizobia inoculation.

\begin{tabular}{lcccc}
\hline Rhizobia inoculant Nodule number plant & Nodule dry weight $\left(\mathrm{mg} \mathrm{plant}^{-1}\right)$ & Shoot dry weight $\left(\mathrm{g}\right.$ plant $\left.^{-1}\right)$ & Root dry weight $\left(\mathrm{g}\right.$ plant $\left.^{-1}\right)$ \\
\hline Isolate 1 & $5 \pm 2.92^{\mathrm{b}}$ & $8.8 \pm 5.68^{\mathrm{b}}$ & $0.60 \pm 0.01^{\mathrm{a}}$ & $0.34 \pm 0.01^{\mathrm{bc}}$ \\
Isolate 2 & 0.0 & 0.0 & $0.32 \pm 0.02^{\mathrm{ab}}$ & $0.20 \pm 0.01^{\mathrm{e}}$ \\
Consortium & $26 \pm 4.53^{\mathrm{a}}$ & $19.6 \pm 2.85^{\mathrm{a}}$ & $0.46 \pm 0.06^{\mathrm{ab}}$ & $0.40 \pm 0.01^{\mathrm{a}}$ \\
USDA 110 & $26 \pm 5.72^{\mathrm{a}}$ & $19.2 \pm 8.06^{\mathrm{a}}$ & $0.50 \pm 0.12^{\mathrm{ab}}$ & $0.36 \pm 0.01^{\mathrm{ab}}$ \\
N treated & 0.0 & 0.0 & $0.33 \pm 0.01^{\mathrm{c}}$ & $0.30 \pm 0.01^{\mathrm{cd}}$ \\
-ve control & 0.0 & 0.0 & $0.23 \pm 0.02^{\mathrm{c}}$ & $0.26 \pm 0.02^{\mathrm{d}}$ \\
\hline$p$ values & $<0.001$ & 0.015 & 0.015 & $<0.001$ \\
\hline
\end{tabular}

Means followed by same lowercase letter(s) are not significantly different at $p<0.05$ (Tukey's HSD test).

not further enhance nodulation and crop performance in the two experiments, this could still be imperative for niche complementarity. The rhizobia isolates used did not show preference for bean cultivars and thus could be used to improve the performance of different bean cultivars.

These two experiments form an important step towards the development of affordable and effective rhizobial inoculants which are well adapted to the local conditions. Therefore, further field studies will elucidate the effectiveness of the rhizobia isolates used at the greenhouse setup.

\section{Competing Interests}

The authors declare that there is no conflict of interests regarding the publication of this paper.

\section{Acknowledgments}

This work was support by Regional Universities Forum for Capacity Building in Agriculture (RUFORUM) 5th Graduate Research Grant (GRG).

\section{References}

[1] The Economist Intelligence Unit, Food security in focus: SubSaharan Africa, 2014, http://foodsecurityindex.eiu.com/.

[2] M. B. Oruru and E. M. Njeru, "Upscaling arbuscular mycorrhizal symbiosis and related agroecosystems services in smallholder farming systems," BioMed Research International, vol. 2016, Article ID 4376240, 12 pages, 2016.

[3] C. Macdonald and B. Singh, "Harnessing plant-microbe interactions for enhancing farm productivity," Bioengineered, vol. 5, no. 1, pp. 5-9, 2014.

[4] T. E. Crews and M. B. Peoples, "Legume versus fertilizer sources of nitrogen: ecological tradeoffs and human needs," Agriculture, Ecosystems and Environment, vol. 102, no. 3, pp. 279-297, 2004.

[5] E. Mugendi, N. Gitonga, R. Cheruiyot, and J. Maingi, "Biological nitrogen fixation by promiscuous soybean (Glycine max L. Merril) in the central highlands of Kenya: response to inorganic fertilizer soil amendments," World Journal of Agricultural Sciences, vol. 6, no. 4, pp. 381-387, 2010.

[6] E. Katungi, A. Farrow, J. Chianu, L. Sperling, and S. Beebe, Common Bean in Eastern and Southern Africa: A Situation and Outlook Analysis, ICRISAT, Nairobi, Kenya, 2009.

[7] FAOSTAT, Food and Agriculture Organization of the United Nations Statistics Division, 2016, http://faostat3.fao.org/browse/ Q/QC/E.
[8] E. M. Njeru, J. M. Maingi, R. Cheruiyot, and G. N. Mburugu, "Managing soybean for enhanced food production and soil biofertility in smallholder systems through maximized fertilizer use efficiency," International Journal of Agriculture and Forestry, vol. 3, no. 5, pp. 191-197, 2013.

[9] J. R. Mugabo, J. Chianu, E. Tollens, and B. Vanlauwe, "Returns to production of common bean, soybean, and groundnut in Rwanda," in Challenges and Opportunities for Agricultural Intensification of the Humid Highland Systems of Sub-Saharan Africa, B. Vanlauwe, P. van Asten, and G. Blomme, Eds., pp. 323333, Springer, Berlin, Germany, 2014.

[10] P. Somasegaran and H. J. Hoben, Handbook for Rhizobia, Springer, New York, NY, USA, 1994.

[11] H. Ögütçü, Ö. F. Algur, E. Elkoca, and F. Kantar, “The determination of symbiotic effectiveness of Rhizobium strains isolated from wild chickpeas collected from high altitudes in Erzurum," Turkish Journal of Agriculture and Forestry, vol. 32, no. 4, pp. 241-248, 2008.

[12] F. Kawaka, M. M. Dida, P. A. Opala et al., "Symbiotic efficiency of native rhizobia nodulating common bean (Phaseolus vulgaris L.) in soils of Western Kenya," International Scholarly Research Notices, vol. 2014, Article ID 258497, 8 pages, 2014.

[13] U. Karaca and R. Uyanoz, "Effectiveness of native Rhizobium on nodulation and growth properties of dry bean (Phaseolus vulgaris L.)," African Journal of Biotechnology, vol. 11, no. 37, pp. 8986-8991, 2012.

[14] M. Mehrpouyan, "Nitrogen fixation efficiency in native strains compared with non-native strains of Rhizobium leguminosarum," in Proceedings of the International Conference on Environment Science and Engineering IPCBEE, vol. 8, pp. 216219, IACSIT Press, Singapore, 2011.

[15] A. Karasu, M. Oz, and R. Dogan, "The effect of bacterial inoculation and different nitrogen doses on yield and yield components of some dwarf dry bean cultivars (Phaseolus vulgaris L.)," Bulgarian Journal of Agricultural Science, vol. 17, no. 3, pp. 296-305, 2011.

[16] M. Ahemad and M. Kibret, "Mechanisms and applications of plant growth promoting rhizobacteria: current perspective," Journal of King Saud University, vol. 26, no. 1, pp. 1-20, 2014.

[17] R. F. Denison and E. T. Kiers, "Lifestyle alternatives for rhizobia: mutualism, parasitism, and forgoing symbiosis," FEMS Microbiology Letters, vol. 237, no. 2, pp. 187-193, 2004.

[18] H. K. Abd El-Maksoud and H. H. Keyser, "Restriction specificity of some soybean genotypes to Bradyrhizobium japonicum serogroups," International Journal of Biological, Biomolecular, Agricultural, Food and Biotechnological Engineering, vol. 4, no. 11, pp. 824-827, 2010. 
[19] M. Hahn and D. Studer, "Competitiveness of a nif ${ }^{-}$Bradyrhizobium japonicum mutant against the wild-type strain," FEMS Microbiology Letters, vol. 33, no. 1, pp. 143-148, 1986. 


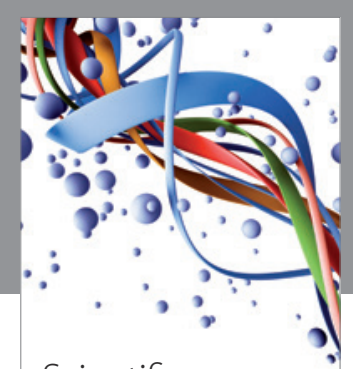

Scientifica
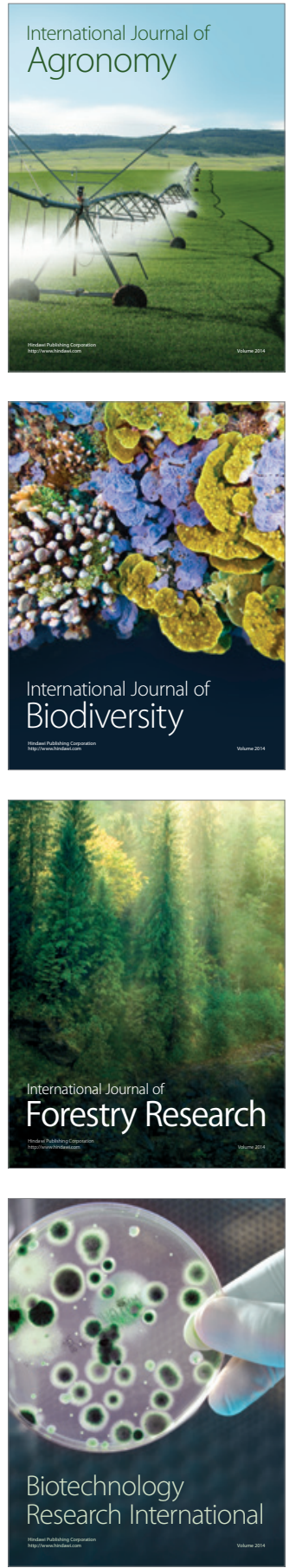
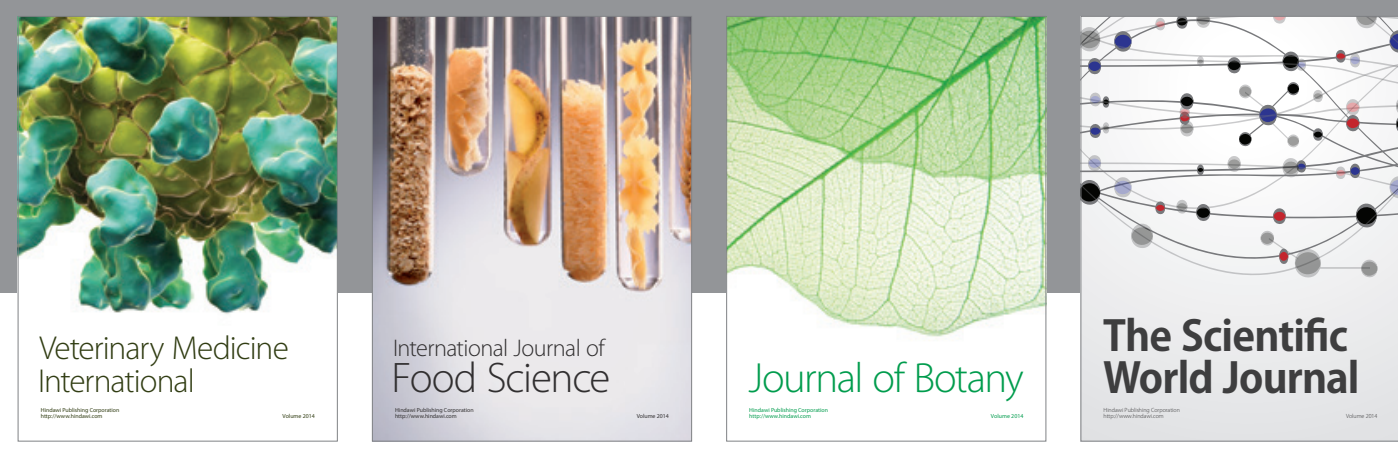

The Scientific

\section{World Journal}

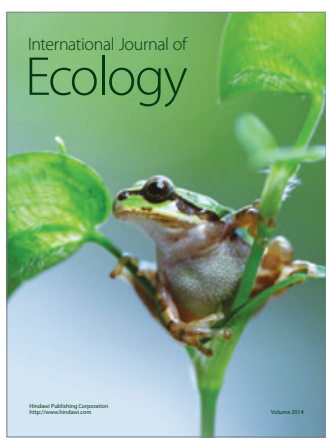

\section{Hindawi}

Submit your manuscripts at

http://www.hindawi.com
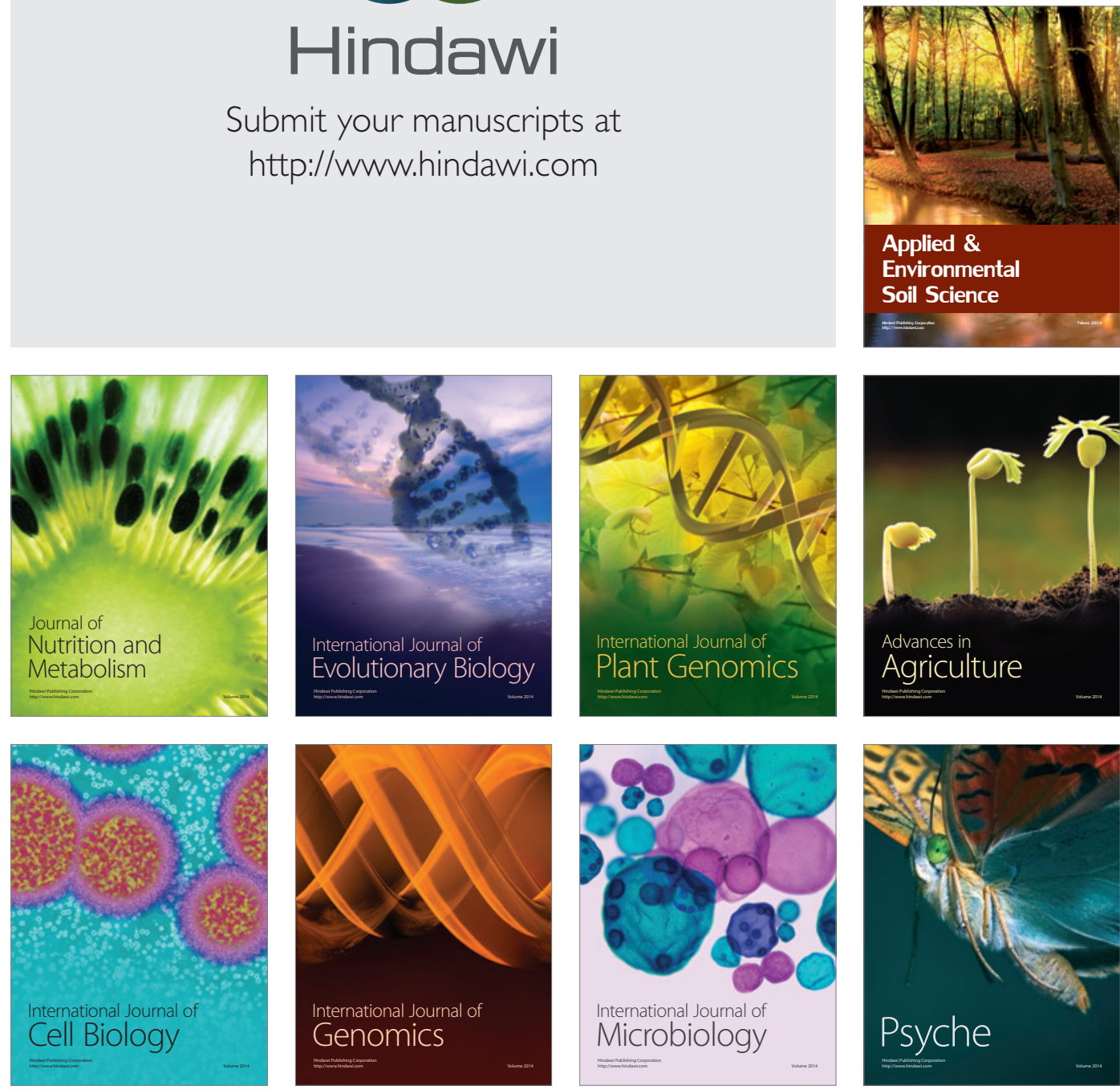
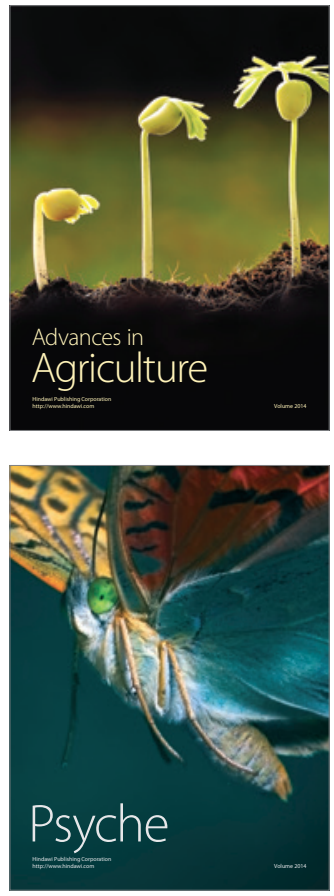